\title{
Development Model of Lifestyles after the Success of Mor Lam's Career
}

\author{
Supap Tinnarat ${ }^{1}$, Sitthisak Champadaeng ${ }^{1} \&$ Urarom Chantamala $^{2}$ \\ ${ }^{1}$ Faculty of Cultural Science, Mahasarakham University, Maha Sarakham, Thailand \\ ${ }^{2}$ Faculty of Fine and Applied Arts, Mahasarakham University, Maha Sarakham, Thailand \\ Correspondence: Supap Tinnarat, Faculty of Cultural Science, Mahasarakham University, Muang District, Maha \\ Sarakham, 44000, Thailand. E-mail: supap.aia@gmail.com
}

Received: June 10, 2013 Accepted: February 28, 2014 Online Published: April 29, 2014

doi:10.5539/ass.v10n9p240 URL: http://dx.doi.org/10.5539/ass.v10n9p240

\begin{abstract}
Problem Statement: As northeastern styled singer, or mor lam have a long role to play in society and culture. Mor lam relates to Isan people's way of life. The objectives of the study were to examine the historical background, the current circumstances and problems of lifestyles and development model of lifestyles after they had achieved highly in career in Isan, Thailand. Approach: The research was carried out in 5 Provinces in Isan or Northeastern Thailand: Khon Kaen, Udon Thani, Ubon Ratchatani, Maha Sarakham, and Roi Et. The instruments used were a basic survey, participant observations, interviews, and focused-group discussions. The 100 informants were key, casual, and general ones respectively. The data analysis was, based on objectives and triangulation technique, done descriptively. Results: Historically, mor lam was basically evolved from four sources: storytelling, exchange of Phaya, soul comforting, and preaching. The storytelling often proceeded with the language of prose and was related to Phaya. There were four types of mor lam: traditional singing, verse singing, dancing with singing, and group singing. Mor lam had roles to play in society as reflected by verses, and singing included their thoughs, way of life, religion, tradition and belief. Ten singers (mor lam) were chosen for the study. They were Khen Dalao, Ratri Srivilai, Thongcharoen Dalao, Bunchuang Denduang, Chaweewan Dumnern, Por Chalard Noi Songserm, Paiboon Siang Thong, Buaphan Daokanong, Ranjuan Duangden, and Krissana Boonsan. All of the mor lam came from rice farming families. They went into professional singers with a passion and received training from parents and relatives. Subsequently, they were trained by famous singing instructors. Based on their expertise in singing, they all became successful, famous and professional singers or mor lam in Thailand.

Currently, most mor lam or traditional singers of all types had to put a lot of effort into staying alive in their singing and entertainment business due to fast technological change and development, such as, media and internet. The public and audiences therefore turned to media and internet for entertainment. To stay on the job, many mor lams had to invest, almost limitless on their singing business. Some mor lam had to reduce the size of their own singing groups and spending.
\end{abstract}

Keywords: development, way of life, success, mor lam

\section{Introduction}

Mor lam was and still is a kind of folk performances passed down from mor lam of previous generations in Isan (Northeastern Thailand). Mor lam was originated from local traditions. In the past, mor lam in Isan had been praised as philosophers of society. They brought together local of society. They brought together local traditions and way of life making them cultural entertainment and Isan identity (Chantabut \& Chantalue, 2004: 11). Mor lam was also known as folk singing, such as the Bang fai parade songs, sorrayapanya hymns, and Korat songs or pleng. Popular as they were and have been, mor lam was and is performed for public entertainment. Mor lam was or is performed during annual festivals, various fairs or merit making. Mor lam expresses both science and arts presenting to the audience not only entertainment but also educating the viewers directly and indirectly providing knowledge and advice about living in the community by adding contents on religion, value, and social norms (Moonisan, 2003: 6). The contents in mor lam's verses, therefore, were composed of literature, philosophy, religion, history, traditions, and flirtation. 
Mor lam (individual, couple or groups of singers) expressed their narrated interaction.

Mor lam also acted as a folk performance providing knowledge and entertainment, recording behavior of people in Isan society, passing down from previous generations, and was rootedly related to the people in Isan. However, no one knew how and when mor lam began in Isan due to a lack of recorded history. Some key informants gave their opinion that mor lam originated by various reasons. In the distant past, Isan people often got together in their village at the end of the day's work discussing about their crop planting or harvesting and urgent problems. Some elderly people had folk tales for them. Most folk tales were related to morale and ethics. The story telling at first was done informally. Later, more people attended the event, the story tellers had to stand up so that the people could see and hear him or them clearly. Some of the stories told were Garagate and Sinsai. Each story teller came up with gestures acting as a hero or herine or a warrior. He or she had to make voice or some accent all along (Thongsook, 2004: 5)

As Isan folk performance, each mor lam used Isan dialect with music played by an instrument, known as "can". Each mor lam performance brought to the audience knowledge, thoughts, enjoyment, morality, and belief. Each mor lam helped to fulfill Isan people's social norms, morality and conserved art and culture. Such role was dominant prior to the introduction of school system in the area.

As a profession, mor lam acted as non-formal education. People learned from mor lam how to be good and responsible citizens and took part in maintaining society. (Khamnate, 1983: 22-23).

Knowledge and life skills reflected by mor lam also included family planning, food and eating habits, health and life-science, and social science, such as, history, geography, occupation, social and cultural values, karma, folk tales, social news, social problem solving, and social participation. Each mor lam learned at early age how to be polite and learn to respect the host and audience (Chamsai et al. 1983: 22-23)

In the past, mor lam were hired to perform locally for various reasons, such as public relations, entertainment, and political campaigns. Politicians chose mor lam as a practical means to reach voters in their constituency. As the Thai society changed, modern media, such as television, radio, internet, newspapers, telephone were popular among city or urban residents. Such media were still limited for the people in rural areas. Mor lam, on the other hand, could gain popularity from rural residents (Boonprasert, 2009: 15). Mor lam could relay stories or government's public policy on governance, health, energy, agriculture, irrigation, and education to the people (Buengsai, 1990: 183).

In the past, mor lam had contributed very greatly to Isan society. They entertained the audiences with a variety of musical melodies and rhythms in their performances. Many mor lam or Isan folk singers were honored ad national artists of various fields.

The problems faced by most mor lam included a decrease of hiring to perform due to various reasons. Some of them were modern media and people's belief and value of mor lam (Natesin, 2007: 56). People had more choices to choose from when it came to information, knowledge, entertainment or other learning resources. Mor lam was not their first choice of entertainment any more. People could watch a movie online or cable, from VCDs or just at a movie house near their homes. Mor lam had to adjust themselves so that they could keep their singing performances and earn some income to support their families. Most mor lam always kept in mind of doing something for their own country, such as setting up a charity or doing some kind of folk education or business. Obviously, many of them had waited for the right time and right place for doing so.

\section{Objectives}

The objectives of the study were to study the historical background of mor lam in Isan, Thailand; to examine the current circumstances and problems of mor lam's lifestyles; and to present development model of lifestyle after they had achieved highly in their career.

\section{Approach}

This qualitative research was carried out in 5 Provinces: Khon Kaen, Udon Thani, Ubon Ratchatani, Maha Sarakham and Roi Et. Ten mor lam or Isan folk singers were casual informants and purposively chosen for the study. There were 90 key and general informants respectively. The data collected using a basic survey, participant observations, interviews, and focused-group discussions. The analysis was based on the research objectives and a triangulation technique.

\section{Results}

For the historical background of mor lam in Isan, the study found that mor lam was a kind of folk singing coupled with Thai-Lao culture which used an instrument known as "can" to be a sound framework for singers. 
As a profession, mor lam continuously developed their singing as entertainment with insertion of news and social and cultural issues. There were two kinds of mor lam: singers that sang or showed dramatically and those that did not. The mor lam that sang or showed dramatically were mor lam phuen and mor lam mu. Mor lam mu were classified as mor lam plern, mor lam khok kha kao, and mor lam ruang thor klawn. Most mor lam learned their profession from close kinsmen, former mor lam, through media, and documentaries. They first learned rhythms and styles. Later, they studied on their own pace until they became skillful mor lam. Since most mor lam came from poor families, becoming famous ones could help them to achieve a better social and economic position.

The current circumstances and problems of mor lam's lifestyles depended on chances and patience of each mor lam. Most mor lam had 4-6 years of primary school education. Few of them had secondary school education. Some, however, continued their education in vocational schools. Many primary school graduates went into learning to be mor lam. Most Isan people back then liked mor lam. They could watch them all night. To learn to be a mor lam was not very difficult. Once they became famous, they held their profession with pride and dignity. They were known for their patience, intelligence, and self-confidence. Higher earnings also lured Isan people to learn to be professional mor lam. Another problem faced by mor lam in Isan was travelling from home very often. Such affected family life; some ended up with a divorce.

For development model of lifestyles after the success of mor lam's career, the researcher suggested four different lifestyles as follows:

1) Most mor lam, if not all, devoted their time, thoughts, and experiences to establish charity, social fund, and various social benefits. The concept behind was that mor lam believed that they were indebted to their homeland. From having little wealth at young age, most mor lam were given opportunities to learn and practice to be professional mor lam. Through hard working, patience, and understanding the value of social, cultural and historical background mor lam composed their own verses and folk songs, which later became very popular among the Isan audiences. Their job as mor lam was solely depended on support, acceptance, and appreciation of the people. It was their turn to do something socially, culturally, and economically meaningful and profitable for the people. Apart from charity and social fund, mor lam intended to give back to their homeland reflecting valuable wisdom and pride of the nation, improvement of current social, economic, and cultural situations, and derivation of peaceful, fair, and happy future for the people.

2) Since mor lam had been paid for 3-5 hour singing performances, the average amount received from the hosts was about 50,000 baht. The highest amount of payment performance was 100,000 baht and the lowest one was about 8,000-10,000 baht. The average number of performances per year for 10 key mor lam was 53 times. Mor lam that performed the highest was mor lam Paiboon Siang Thong (100 times per year). Mor lam Khen Dalao performed only 25-30 times per year due to his old age. Based on such accumulated income, 5 out of 10 mor lam had planned ahead investing on long lasting business, such as home stays, real estate, studio recording services, mixed farming, and building convention-halls for public uses. The concept behind such investment was that mor lam wanted to tell the public that they could give something back to the people in return for what people had done to them. It was a win-win philosophy

3) Mor lam set up network or association to assist mor lam who needed help most and moved on with teaching and training younger mor lam before time was running short for some of them. As they taught younger mor lam, the experienced mor lam shared with them Isan social and cultural values as well as showed them how mor lam could do more for their country, such as in education and entertainment by giving speeches, lectures, singing lessons or trainings. For their own singing performances, they chose to perform or sing 2-3 hours rather than 5-6 hours like they did in the past. They saved time for related activities, such as song composition, teaching, and training mor lam

4) Mor lam spent time assisting local as well as national governments running campaigns on various emerging programs on job, social, cultural, economic, health, environmental, and educational improvement; drug and crime prevention. The concept behind that came from the fact that mor lam knew and unstood the people's needs more than anybody else in Isan, Thailand. Mor lam, according to this research, were sitting on heart and mind of the people. They knew well how the people felt about what was happening around them and their community. The people had trust in Mor lam. They therefore were willing to listen to mor lam's advice. In short, mor lam had powerful and realistic voice matching the government and people's needs. Since most mor lam lived in rural areas or closer to towns or urban areas, they were easily access able for the people and themselves were able to move around visiting all parties involved. Viewed from this light, mor lam were happy to see that their role advice, and help go forward benefiting Isan people and Isan region. 


\section{Discussion}

1) Historically, mor lam or Isan folk singers had been part of Isan culture. They presented various contents on social, cultural, historical, economic, and political aspects. In fact, they turned such knowledge and information into entertainment, public relations, political and health campaigns. Mor lam could be performed by one singer, a couple, or as a group and they changed as a result of social and cultural as a result of social and cultural change. Each type of mor lam had to adjust themselves so that they could move along and served their community and society. Such was consistent with Miller (1998: 325-327) that lam plern, a type of Isan mor lam, was adapted from mor lam klawn. Mor lam situation in Laos, on the other hand, was able to move along satisfying the needs of society using lam klawn presenting history, geography, and literature. As for the role of mor lam in Isan, the finding was consistent with Jaruwan Dhammawat (1985: 211), Sitthisak Champadaeng (2005), Supap Thinnarat (2010), that mor lam had been part of Isan reflecting social norms, thoughts, social change, problem solving, and political and moral campaign respectively

2) For current circumstances and problems of mor lam's lifestyles, the study revealed that traditional mor lam had to adjust themselves and their performances in order to survive due to social, economic, and technological change, and high cost of management. Many mor lam failed in doing so. Those who succeeded had to reduce the management cost and focused on entertainment more than anything else. Such was consistent with Benedict (1934) that people were different from one another due to personality, taste, political power, and income earnings. By accepting social and economic reality of the time, each mor lam could maintain themselves based on personal feelings, attitude, value, and ideology. Such was consistent with Pornsiri Sriorapim (2008: 61-64) that people adopted new things including behavior due to their own understanding, knowledge, attitude and value.

3) For development model of mor lam's lifestyle after they had achieved highly in their profession, the research proposed four consecutive development areas: mor lam performing styles, professional security, ethics, and self-realization.

a) Performing styles included styles of singing, appropriate contents, melody and versification, dress and personality.

b) For development of professional security, mor lam needed to have good teachers around for advice and job improvement. It was important that mor lam did what they could society, such as setting up welfare fund, singing network, scholarship for school children. Such was consistent with Wanpen Saengpan (2002) that mor lam should be a good role model to children as well as adults, such as respect their former teachers, hard working, and take care of their families with warmth and support.

c) Within the ethics and self-realization, mor lam needed to have initiation, self-intimacy and self-competence.

d) Amidst fast changing society, mor lam needed to have full adaptation, goal attainment, integration of all sciences, and keeping the good things in their own profession.

\section{References}

Boonprasert, P. (2009). Mo Lam: Folk Media. A Thesis. Maha Sarakham: Mahasarakham University.

Buengsai, S. (1990). The Role of Mo Lam Klawn in Politics. A Thesis. Maha Sarakham: Mahasarakham University.

Champadaeng, S. (2005). The Role of Mo Lam in Solving Social Problems. A Thesis. Maha Sarakham: Mahasarakham University.

Chamsai et al. (1983). Folklore and All Types of Mo Lam, Amphoe Khon Sawan, Chaiyaphum Province. Bangk: Aksorn Chareonthat.

Chantabut, S., \& Chantalue, T. (2004). Status and Role of Mo Lam Amidst Social Change. A Case Study of Ubon Ratchatani.

Dhammawat, J. (1985). Isan Wisdom. Maha Sarakham: Nang Nual Offset.

Miller, T. E., \& Chonpairot, J. (1944). A History of Siam Music Reconstructed From Western Document 1505-1932. Center for Southeast Asian Studies: Northern Illinois University

Moonisan, C. (2003). World Views in Folk Songs Presented in Jinthara Poonlap. A Thesis. Maha Sarakham: Mahasarakham University.

Natesin, S. (2007). Development of Folk Singing, Khon Kaen Style, Rabiab Watasil. A Thesis. Maha Sarakham: Mahasarakham University. 
Sriorapim, P. (2008). Application of Wisdom of Folk Performance of Phaya, Mukdahan Province for Promotion of Local Culture. A Thesis. Maha Sarakham: Mahasarakham University.

Thinnarat, S. (2010). Political Media: A Case Study of Role of Mo Lam Towards 2001-2009 Province. A Thesis. Maha Sarakham: Mahasarakham University.

Thongsook, B. (2004). Cultural Heritage. Bangkok: Rung Ruang San Khanphim.

\section{Copyrights}

Copyright for this article is retained by the author(s), with first publication rights granted to the journal.

This is an open-access article distributed under the terms and conditions of the Creative Commons Attribution license (http://creativecommons.org/licenses/by/3.0/). 